\title{
Nonlinear Stability Calculation Method of Crane Lattice Boom with Large Slenderness Ratio
}

\author{
Ge-Ning XU ${ }^{1}$, Zhong-Yuan KANG ${ }^{1, a,{ }^{*}, \text { Heng } \mathrm{YANG}^{1}, \text { Xin WANG }}{ }^{2}, \mathrm{Jing} \mathrm{LI}^{3}$ \\ ${ }^{1}$ College of Mechanical Engineering, Taiyuan University of science and Technology, 030024 \\ Taiyuan, China \\ ${ }^{2}$ College of Mechanical Engineering, Dalian University of Technology, 116024 Dalian, China \\ ${ }^{3}$ Bery Heavy Industries Co., Ltd, 116024 Dalian, China \\ akangzhongyuan199@sina.com \\ ${ }^{*}$ Corresponding author
}

Keywords: Large slenderness ratio; Stability; Nonlinear; Limit state method; Generalized margin.

\begin{abstract}
Aiming at the stability problem of crane lattice boom with large slenderness ratio, the applicability and practicability of four kinds of design theories and methods (the allowable stress method based on linear theory, the allowable stress method based on nonlinear theory, the limit state method based on linear theory and the limit state method based on nonlinear theory) are studied by taking VS2012 as development platform and programming multi-theoretical software for the stability calculation of crane lattice boom with large slenderness ratio using C\# programming language. The optimal theory and method are obtained by comparing the generalized margin of above four methods. Practical example results show that the limit state method based on nonlinear theory has the minimum generalized margin and highest material utilization on the premise of meeting the stability of boom which illustrates the linear theory based on small displacement assumption is unsuitable for the stability design calculation of lattice boom with large slenderness ratio while the limit state method based on nonlinear theory is more suitable for the occasion that the relationship between load and internal force is nonlinear and the calculation results are more in line with actual situation. Finally, the optimal theory and methods are verified through ANSYS, it can be found that analytic results are in good agreement with finite element results which further explains the suitability and practicability of the limit state method based on nonlinear theory.
\end{abstract}

\section{Introduction}

Due to the demand in the fields of wind and electricity power, metallurgy, petrochemical industry, etc, and for large-scale lifting operation, the load capacity of a crane tends to be heavier; but itself tends to be lighter, also it will have the features of larger space and higher efficiency. The application of high-strength steel not only makes crane boom structure more lightweight but also makes the flexibility of structure increased and geometry deformation under heavy load nonlinear. As a result, the translational displacement, rotational displacement and strain are no longer infinite small, and the constitutive relation presents a strong nonlinear. If the linear theory based on the assumption of small displacement is still used to analyze the stability of boom structure, the results will deviates from actual stress state which will cause an unsafe or incorrect statistic. Moreover, from structural mechanics perspective, strictly speaking, linear problem is a special case of nonlinear problems, and linear assumption is only a simplification of practical engineering problems. Practical engineering problems such as the research on elastic-plastic dynamic response of the structure under earthquake, wind resistance of high-rise building, dynamic stability of large 
span reticulated shell, form finding and cutting analysis of cable membrane structure, and wind-induced vibration of large bridges are just assumed as linear problem are not enough, and further consideration is required for nonlinear problems. Therefore, the nonlinear analysis of various engineering structures is necessary and increasingly important. The stability analysis of crane lattice boom structure, which belongs to biaxial bending, need to consider the effects of geometric non-linearity because of larger slenderness ratio and smaller stiffness $[1,2]$.Meanwhile, as the increase of steel yield limit, the conversion slenderness ratio of boom rises constantly while the stability coefficient decreases, which have highlighted structural stability issues [3]. To solve the challenging problems above, it is necessary to study stability calculation method

\section{Stability calculation of crane lattice boom}

The stability of crane metal structure is one of the important indicators to measure whether structure is out of operation [3]. Hence, when conducting stability calculation of crane metal structure, close calculation formulas with actual stress state should be given. Due to smaller stiffness, when subjected to heavy load, structure will have a larger deformation which will lead to a nonlinear geometric relationship between the load and displacement, however, the relationship between the stress and strain of material is still linear-elastic. Therefore, the stability of boom structure belongs to the category of geometric nonlinear mechanics so that the second order nonlinear analysis should be adopted.

Overall Stability. The lattice boom structure presents a significant second order effect when bearing both transverse and axial load so the additional bending moment caused by initial defect and axial compression must be involved in stability calculation. When using the limit state method based on nonlinear theory to calculate the overall stability, NEx and NEy, within the increase coefficient $\left(1-\gamma_{m} N / N_{E x}, 1-\gamma_{m} N / N_{E y}\right)$ should be divided by the resistance coefficient $\gamma_{m}$. The computation formula is as follow [3]:

$$
\frac{N}{\varphi A}+\frac{M_{x}(z)}{\left(1-1-\gamma_{m} N / N_{E x}\right) W_{x}(z)}+\frac{M_{y}(z)}{\left(1-1-\gamma_{m} N / N_{E y}\right) W_{y}(z)} \leq \lim \sigma
$$

Where, $\mathrm{N}$ is the axial force of boom, $\mathrm{A}$ is the cross-sectional area, limo is the limit stress value of material, NEx is the critical force in amplitude plane, NEy is the critical force in rotary plane, $\operatorname{Mx}(\mathrm{z})$ is the basic moment of section $\mathrm{z}$ produced in amplitude plane, $\mathrm{My}(\mathrm{z})$ is the basic moment of section $\mathrm{z}$ produced in rotary plane, $\mathrm{Wx}(\mathrm{z})$ is the section modulus in bending of lattice boom section to the $\mathrm{x}$ axis, $\mathrm{Wy}(\mathrm{z})$ is the section modulus in bending of lattice boom section to the $\mathrm{y}$ axis, ${ }^{\varphi}$ is the stability coefficient determined by cross section type and maximum slenderness ratio $\lambda$ or hypothetical slenderness ratio $\lambda \mathrm{F}$.

The calculation formula of the stability coefficient ${ }^{\varphi}$ is as follows:

$$
\varphi=\left\{\begin{array}{l}
1-\alpha_{1} \lambda_{n}^{2}, \lambda_{n}=\frac{\lambda}{\pi} \sqrt{\sigma_{s} / E} \leq 0.215 \\
\frac{1}{2 \lambda_{n}^{2}}\left[\left(\alpha_{2}+\alpha_{3} \lambda_{n}+\lambda_{n}^{2}\right)-\sqrt{\left(\alpha_{2}+\alpha_{3} \lambda_{n}+\lambda_{n}^{2}\right)^{2}-4 \lambda_{n}^{2}}\right], \lambda_{n}>0.215
\end{array}\right.
$$

Where, $\alpha 1, \alpha 2$ and $\alpha 3$ are the calculation coefficient determined by the cross section type, $\lambda \mathrm{n}$ is the regular slenderness ratio [3]. 


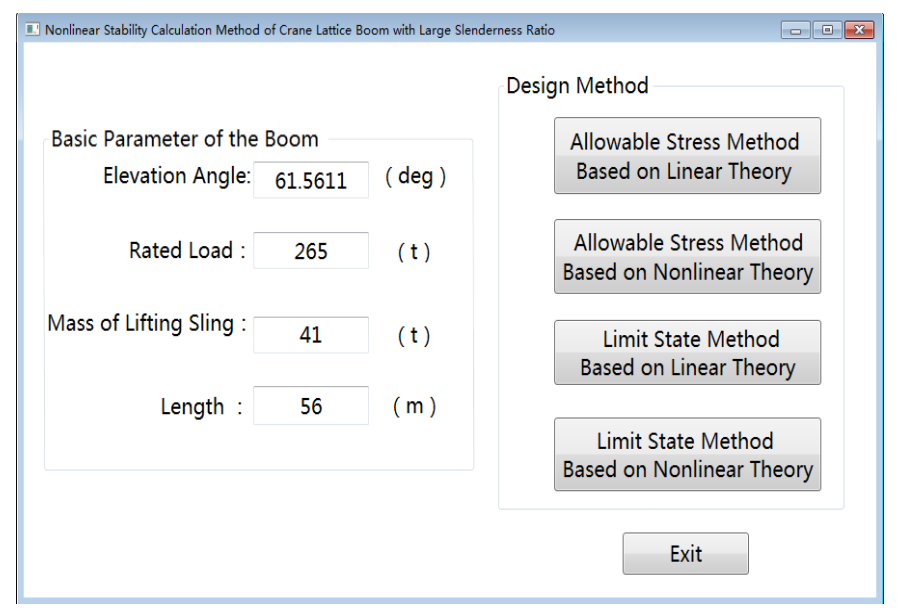

Fig. 1. Software interface

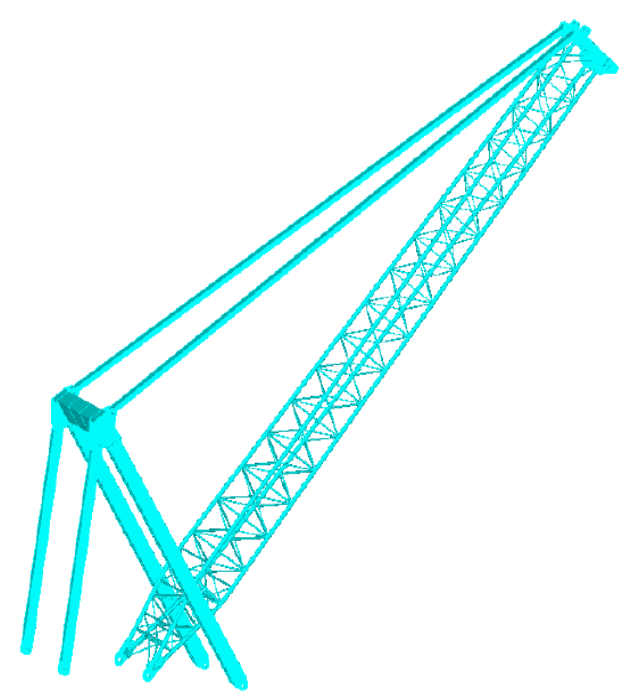

Fig.2. 290t lattice boom crane

Single Limb Stability. For statically determinate structure, the single limb instability will cause the evolution from the initial structure geometric construction to geometrically unstable system. Structure with low load-carrying capacity cannot maintain the initial equilibrium shape which definitely results in instability of the whole structure. For statically indeterminate structures, the individual single limb instability does not necessarily cause instability of the whole structure, but the internal force bore by above unstable single limb will be transferred to other single limb which will buckle when another new limit state is reached, similar processes continue to evolve and the number of unstable single limb accumulates continuously until enough to induce the overall instability. For crane lattice boom system, a higher statically indeterminate structure which consists of many delicate beams and columns and the overall instability can be seen as constant accumulation of the single limb instability, so it is considerable to implement the single limb stability calculation. The computation formula is as follow [3]:

$$
\frac{1}{A_{x} \varphi}\left[\frac{N}{4}+\frac{M_{x}(z)}{2\left(1-\gamma_{m} N / N_{E x}\right) B}+\frac{M_{y}(z)}{2\left(1-\gamma_{m} N / N_{E y}\right) H}\right] \leq \lim \sigma
$$

Where, Ax is the single limb cross-sectional area, $\mathrm{B}$ and $\mathrm{H}$ are the width and height of calculation section respectively. 


\section{Parametric realization and calculation process}

With Microsoft Visual Studio 2012 as development platform, calculation software based on multi-theory and multi-method for the crane lattice boom stability was developed by using C\# language, as shown in Fig. 1. The calculation process is as follows:

1) Build the mechanical analytical model of lattice boom, then on the basis of the working characteristics of lattice boom, do load analysis and load combinations, and determine the corresponding safety coefficient and resistance coefficient.

2) Program calculation software based on four design theories and methods (the allowable stress method based on linear theory, the allowable stress method based on nonlinear theory, the limit state method based on linear theory and the limit state method based on nonlinear theory).

3) Input the working condition (elevation angle, lifting weight and other basic parameters), and select suitable calculation method for analytical calculation.

4) Output the stability calculation report about the dangerous section in the form of text.

5) Obtain the optimum theory and method by comparing the generalized margin of various methods.

\section{Engineering example}

Taking 290t lattice boom crane (28 kinds of working conditions) provided by an enterprise load combinations B1 as an engineering example, as shown in Fig. 2. Load and load combinations B [4] are shown in Table 1.

Table 1. Load and load combinations B of lattice boom crane based on limit state method

\begin{tabular}{|c|c|c|c|c|c|c|c|c|}
\hline \multirow{2}{*}{\multicolumn{3}{|c|}{ List of Loads }} & \multicolumn{6}{|c|}{ Load combinations B } \\
\hline & & & Partial load factors & B1 & B2 & B3 & B4 & B5 \\
\hline \multirow{2}{*}{$\begin{array}{l}\text { Gravity acceleration and } \\
\text { impacts }\end{array}$} & \multicolumn{2}{|c|}{ Mass of boom } & $\gamma_{P B 1}=1.16$ & $\varphi_{1}$ & $\varphi_{1}$ & 1 & - & - \\
\hline & \multicolumn{2}{|c|}{ Mass of rated load } & $\gamma_{P B 2}=1.28$ & $\varphi_{2}$ & $\varphi_{3}$ & 1 & - & - \\
\hline \multirow{2}{*}{ Acceleration from drives } & \multirow{2}{*}{$\begin{array}{l}\text { Mass of boom and rated } \\
\text { load }\end{array}$} & $\begin{array}{l}\text { Hoist drives } \\
\text { excluded }\end{array}$ & $\gamma_{P B 3}=1.48$ & $\varphi_{5}$ & $\varphi_{5}$ & - & $\varphi_{5}$ & - \\
\hline & & $\begin{array}{l}\text { Hoist drives } \\
\text { included }\end{array}$ & $\gamma_{P B 4}=1.48$ & - & - & $\varphi_{5}$ & - & - \\
\hline \multicolumn{3}{|c|}{ In-service wind } & $\gamma_{P B 5}=1.16$ & 1 & 1 & 1 & 1 & 1 \\
\hline \multicolumn{3}{|c|}{ Resistance coefficient } & \multicolumn{6}{|c|}{$\gamma_{m}=1.1$} \\
\hline \multicolumn{3}{|c|}{ High risk coefficient } & \multicolumn{6}{|c|}{$\gamma_{n}=1.1$} \\
\hline
\end{tabular}

Three dangerous sections (the head section, the center of gravity section, the root section) are selected, and the key parameters of each dangerous section are listed in Table 2. Based on two theories and two methods, the stress of the overall stability and single limb stability of each dangerous section are rapidly and accurately calculated by using the compiled software. Due to space limitations, there will only be the stability stress calculation results of 6 kinds of typical working conditions (as shown in Table 3) given, listed in Table 4.

Table 2. Parameter of dangerous section

\begin{tabular}{|c|c|c|c|c|c|}
\hline $\begin{array}{c}\text { Location of } \\
\text { dangerous section }\end{array}$ & $\begin{array}{c}\text { Cross-sectional } \\
\text { area/mm2 }\end{array}$ & Height/mm & Width/mm & $\begin{array}{c}\text { Equivalent slenderness } \\
\text { Ratio } \lambda_{h x}\end{array}$ & $\begin{array}{c}\text { Equivalent slenderness } \\
\text { Ratio } \lambda_{h y}\end{array}$ \\
\hline head & 59208 & 2900 & 1776 & \multirow{2}{*}{4} & \multirow{2}{*}{48} \\
\hline center of gravity & 59208 & 2900 & 3477 & & \\
\hline root & 59208 & 967 & 5000 & & \\
\hline
\end{tabular}


Table 3. Typical working conditions table

\begin{tabular}{|c|c|c|c|}
\hline Condition No. & Rated capacity/t & Radius/m & Elevation angle $/^{\circ}$ \\
\hline 1 & 265 & 38.88 & 74.0840 \\
\hline 2 & 265 & 55.00 & 66.0006 \\
\hline 3 & 265 & 63.50 & 61.5611 \\
\hline 4 & 250 & 66.00 & 60.2242 \\
\hline 5 & 240 & 69.00 & 58.5982 \\
\hline 6 & 130 & 99.89 & 39.6627 \\
\hline
\end{tabular}

Table 4. Results of stability calculation

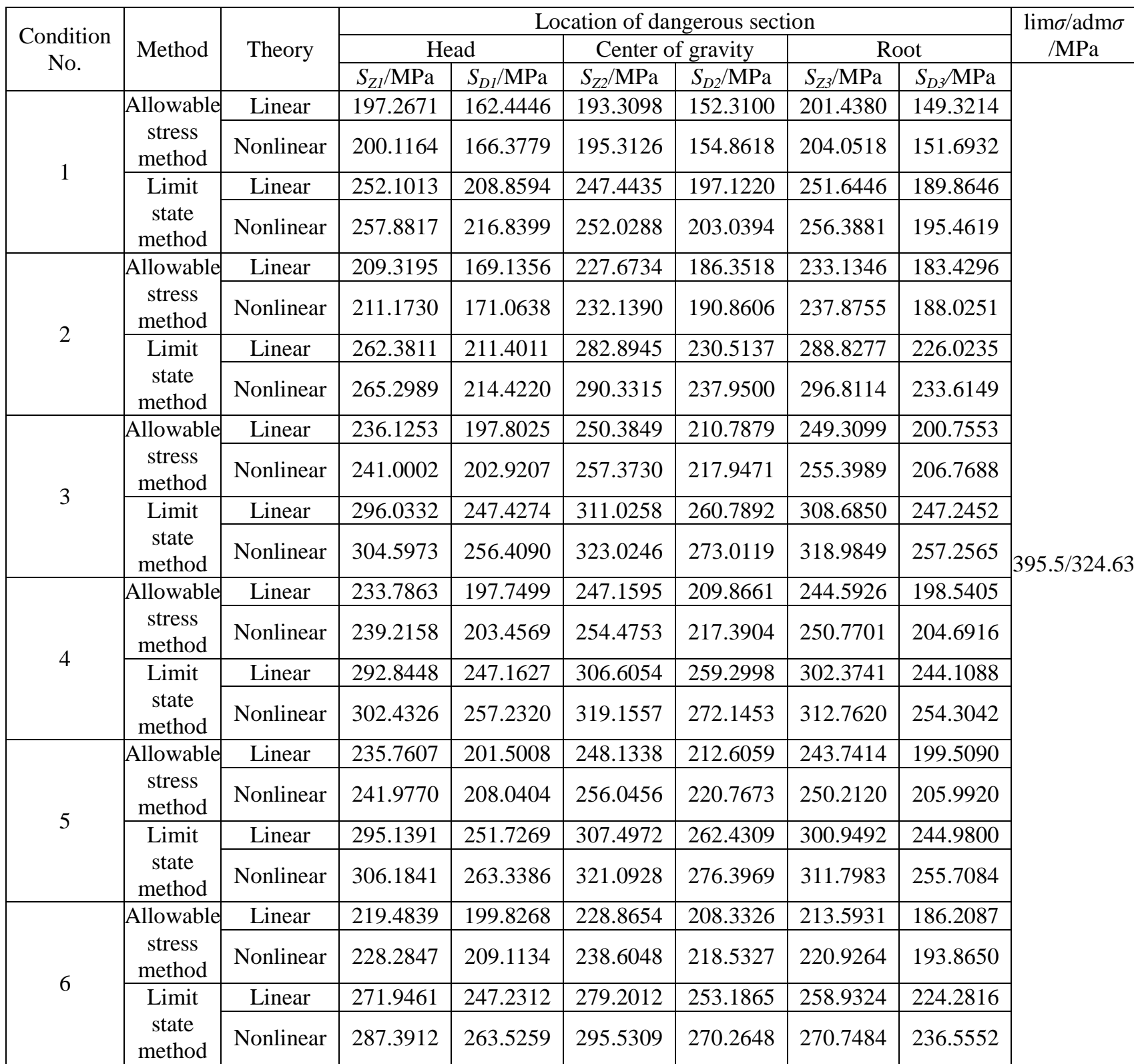

Note: $\mathrm{SZi}(\mathrm{i}=1,2,3)$ represents the stress of the overall stability, $\mathrm{SDi}(\mathrm{i}=1,2,3)$ represents the stress of the single limb stability, admo is the allowable stress.

In order to compare the material utilization, strength reserve and dangerous condition under different design methods, the concept of generalized margin is introduced.

For allowable stress method, the definition of generalized margin is as follow:

$n_{\sigma}=1-\sigma / \operatorname{adm} \sigma$

For limit stress method, the definition of generalized margin is as follow: 
$n_{\sigma}=1-\sigma / \lim \sigma$

According to above definition, the generalized margin of each method is gotten from Table 4, listed in Table 5.

Table 5. Generalized margin of each method

\begin{tabular}{|c|c|c|c|c|c|c|c|c|}
\hline \multirow{3}{*}{$\begin{array}{l}\text { Condition } \\
\text { No. }\end{array}$} & \multirow{3}{*}{ Method } & \multirow{3}{*}{ Theory } & \multicolumn{6}{|c|}{ Location of dangerous section } \\
\hline & & & \multicolumn{2}{|c|}{ Head } & \multicolumn{2}{|c|}{ Center of gravity } & \multicolumn{2}{|c|}{ Root } \\
\hline & & & $n_{Z 1}$ & $n_{D 1}$ & $n_{\mathrm{Z} 2}$ & $n_{D 2}$ & $n_{Z 3}$ & $n_{D 3}$ \\
\hline \multirow{4}{*}{1} & \multirow{2}{*}{$\begin{array}{c}\text { Allowable } \\
\text { stress method }\end{array}$} & Linear & 0.3923 & 0.4996 & 0.4045 & 0.5308 & 0.3795 & 0.5400 \\
\hline & & Nonlinear & 0.3836 & 0.4875 & 0.3984 & 0.5230 & 0.3714 & 0.5327 \\
\hline & \multirow{2}{*}{$\begin{array}{l}\text { Limit state } \\
\text { method }\end{array}$} & Linear & 0.3626 & 0.4719 & 0.3744 & 0.5016 & 0.3637 & 0.5199 \\
\hline & & Nonlinear & 0.3480 & 0.4517 & 0.3628 & 0.4866 & 0.3517 & 0.5058 \\
\hline \multirow{4}{*}{2} & \multirow{2}{*}{$\begin{array}{c}\text { Allowable } \\
\text { stress method }\end{array}$} & Linear & 0.3552 & 0.4790 & 0.2987 & 0.4260 & 0.2818 & 0.4350 \\
\hline & & Nonlinear & 0.3495 & 0.4730 & 0.2849 & 0.4121 & 0.2672 & 0.4208 \\
\hline & \multirow{2}{*}{$\begin{array}{c}\text { Limit state } \\
\text { method }\end{array}$} & Linear & 0.3366 & 0.4655 & 0.2847 & 0.4172 & 0.2697 & 0.4285 \\
\hline & & Nonlinear & 0.3292 & 0.4578 & 0.2659 & 0.3984 & 0.2495 & 0.4093 \\
\hline \multirow{4}{*}{3} & \multirow{2}{*}{$\begin{array}{c}\text { Allowable } \\
\text { stress method }\end{array}$} & Linear & 0.2726 & 0.3907 & 0.2287 & 0.3507 & 0.2320 & 0.3816 \\
\hline & & Nonlinear & 0.2576 & 0.3749 & 0.2072 & 0.3286 & 0.2133 & 0.3631 \\
\hline & \multirow{2}{*}{$\begin{array}{l}\text { Limit state } \\
\text { method }\end{array}$} & Linear & 0.2515 & 0.3744 & 0.2136 & 0.3406 & 0.2195 & 0.3749 \\
\hline & & Nonlinear & 0.2298 & 0.3517 & 0.1833 & 0.3097 & 0.1935 & 0.3495 \\
\hline \multirow{4}{*}{4} & \multirow{2}{*}{$\begin{array}{c}\text { Allowable } \\
\text { stress method }\end{array}$} & Linear & 0.2798 & 0.3908 & 0.2386 & 0.3535 & 0.2465 & 0.3884 \\
\hline & & Nonlinear & 0.2631 & 0.3733 & 0.2161 & 0.3303 & 0.2275 & 0.3695 \\
\hline & \multirow{2}{*}{$\begin{array}{l}\text { Limit state } \\
\text { method }\end{array}$} & Linear & 0.2596 & 0.3751 & 0.2248 & 0.3444 & 0.2355 & 0.3828 \\
\hline & & Nonlinear & 0.2353 & 0.3496 & 0.1930 & 0.3119 & 0.2092 & 0.3570 \\
\hline \multirow{4}{*}{5} & \multirow{2}{*}{$\begin{array}{c}\text { Allowable } \\
\text { stress method }\end{array}$} & Linear & 0.2738 & 0.3793 & 0.2356 & 0.3451 & 0.2492 & 0.3854 \\
\hline & & Nonlinear & 0.2546 & 0.3591 & 0.2113 & 0.3199 & 0.2292 & 0.3655 \\
\hline & \multirow{2}{*}{$\begin{array}{c}\text { Limit state } \\
\text { method }\end{array}$} & Linear & 0.2538 & 0.3635 & 0.2225 & 0.3365 & 0.2391 & 0.3806 \\
\hline & & Nonlinear & 0.2258 & 0.3342 & 0.1881 & 0.3011 & 0.2116 & 0.3535 \\
\hline \multirow{4}{*}{6} & \multirow{2}{*}{$\begin{array}{c}\text { Allowable } \\
\text { stress method }\end{array}$} & Linear & 0.3239 & 0.3844 & 0.2950 & 0.3582 & 0.3420 & 0.4264 \\
\hline & & Nonlinear & 0.2968 & 0.3558 & 0.2650 & 0.3268 & 0.3195 & 0.4028 \\
\hline & \multirow{2}{*}{$\begin{array}{l}\text { Limit state } \\
\text { method }\end{array}$} & Linear & 0.3124 & 0.3749 & 0.2941 & 0.3598 & 0.3453 & 0.4329 \\
\hline & & Nonlinear & 0.2733 & 0.3337 & 0.2528 & 0.3167 & 0.3154 & 0.4019 \\
\hline
\end{tabular}

Note: $n_{Z i}(i=1,2,3)$ represents the generalized margin of the overall stability, $n_{D i}(i=1,2,3)$ represents the generalized margin of the single limb stability.

To visually compare and analyze the difference among the generalized margin of each method, the data-changing tendency of Table 5 is shown in Fig. 3.

From Fig. 3, it can be seen that the generalized margin values based on 4 calculation methods, 6 calculation conditions, 3 calculation cross sections, and 2 calculation items are all less than 1, which indicates that the stability of boom can meet the design specification requirements. The limit state method based on nonlinear theory has the minimum generalized margin, which proves that the geometrical deformation of lattice boom structure is nonlinear, when this method is used to calculate the stability of boom, it can not only give full play to the bearing capacity of material, but also has a reliable generalized margin. Structural nonlinearity decreases as the elevation angle reduces, as a result, the gap between the generalized margin of limit state method based on nonlinear theory and allowable stress method based on nonlinear theory is narrowing. To fully explain the reasons for above phenomenon, an analysis of overall stability stress of the limit state method based on nonlinear theory and allowable stress method based on nonlinear theory is implemented, each stress is shown in Table 6 and Table 7. 


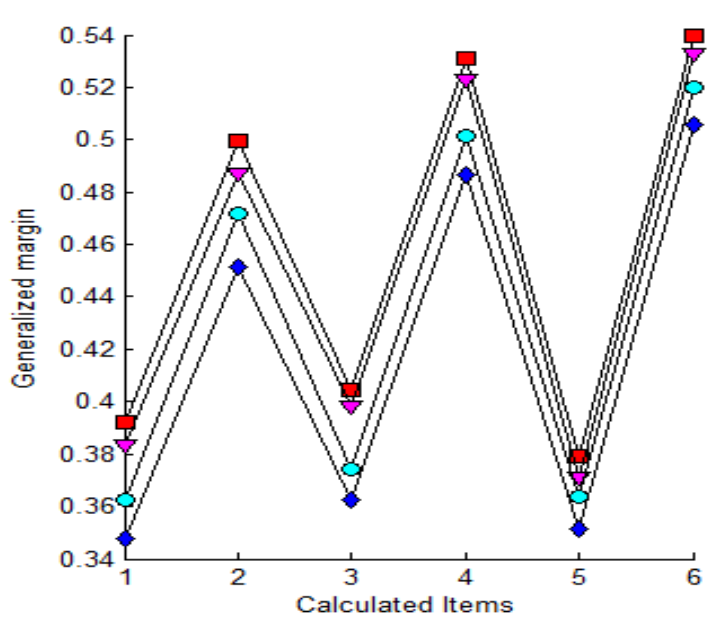

(a) Comparison of generalized margin of condition No.1

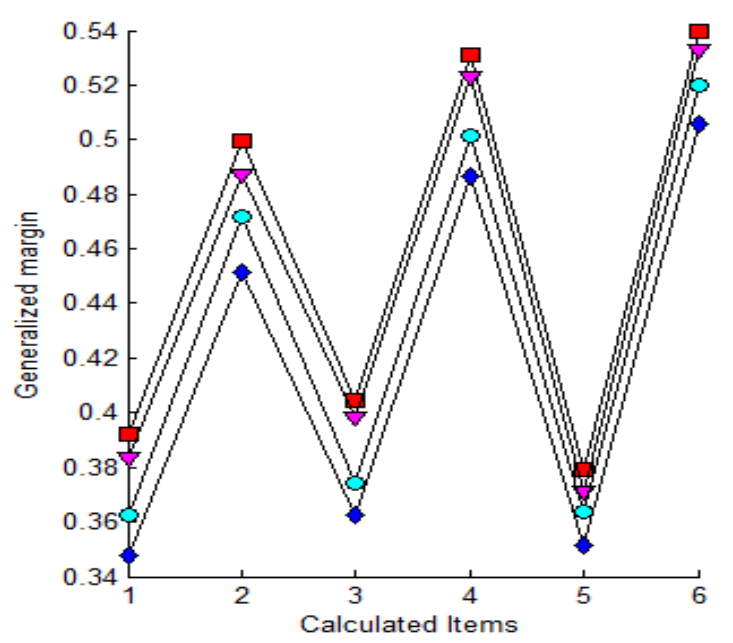

(c) Comparison of generalized margin of condition No.3

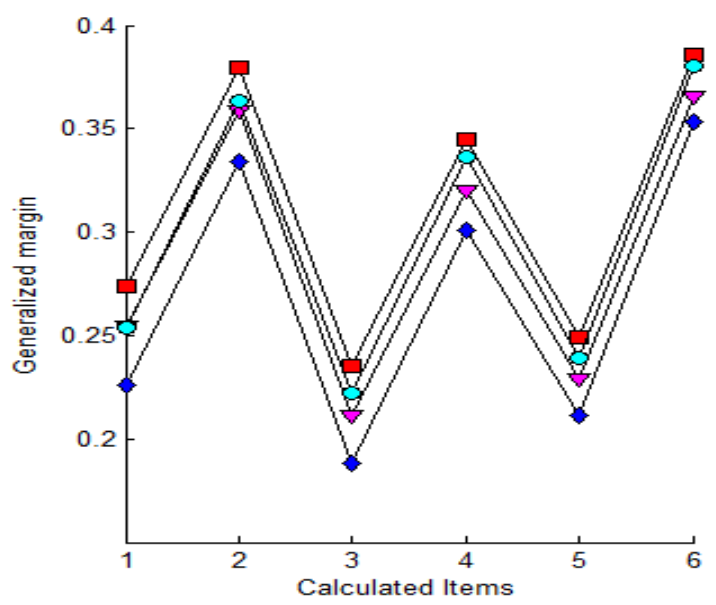

(e) Comparison of generalized margin of condition No.5

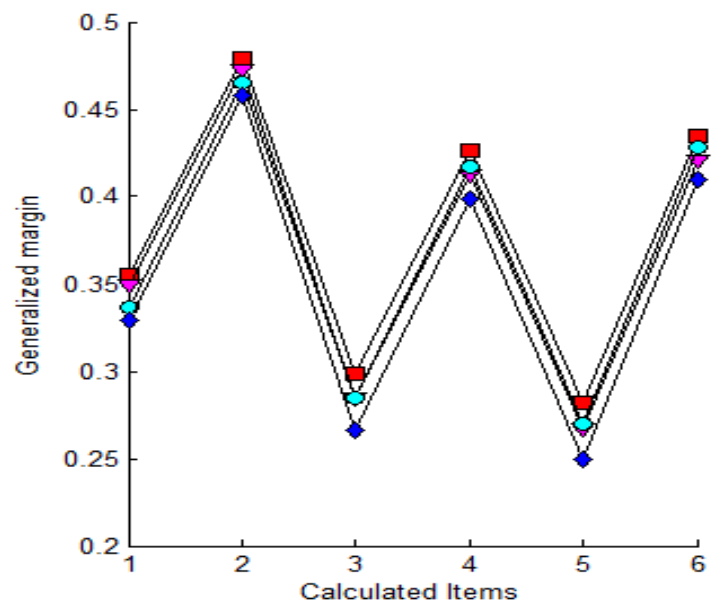

(b) Comparison of generalized margin of condition No.2

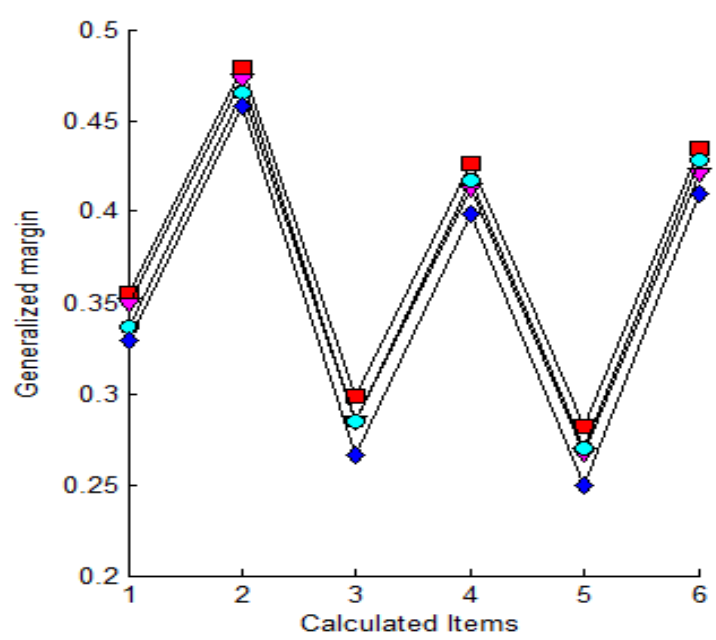

(d) Comparison of generalized margin of condition No.4

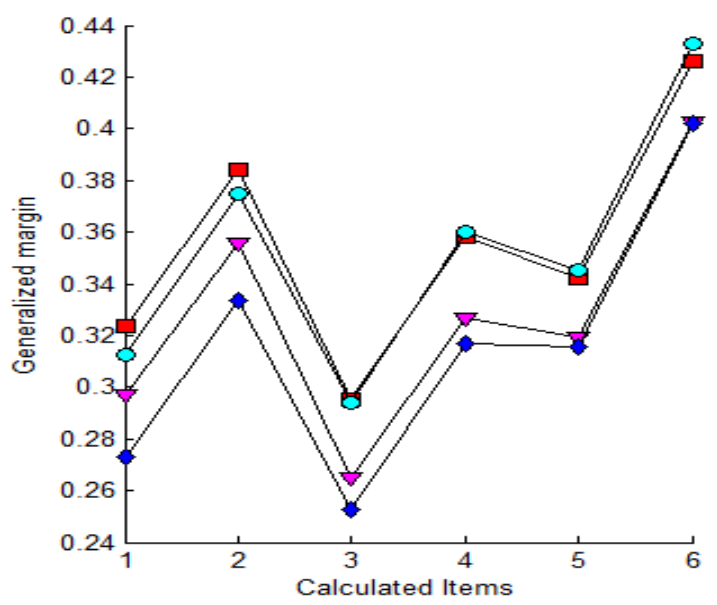

(f) Comparison of generalized margin of condition No.6

The generalized margin of allowable stress method based on linear theory $\rightarrow$ The generalized margin of allowable stress method based on nonlinear theory $-\rightarrow$ The generalized margin of limit state method based on linear theory $\rightarrow$ The generalized margin of limit state method based on nonlinear theory.

Note: The horizontal axis digital 1 to 6 respectively corresponds to the data $\left(n_{Z i}, n_{D i}\right)$ in Table 5

Figure 3. Comparison of generalized margin of each working condition 
Table 6. Analysis of the overall stability stress of limit state method based on nonlinear theory

\begin{tabular}{|c|c|c|c|c|c|c|c|}
\hline \multicolumn{2}{|c|}{ Condition No. } & 1 & 2 & 3 & 4 & 5 & 6 \\
\hline \multirow{3}{*}{$\begin{array}{c}\text { The head } \\
\text { dangerous } \\
\text { section }\end{array}$} & Total stress & 257.8817 & 265.2989 & 304.5973 & 302.4326 & 306.1841 & 287.3912 \\
\cline { 2 - 8 } & Axial stress & 224.1320 & 251.0002 & 264.3469 & 255.9979 & 252.0449 & 188.6587 \\
\cline { 2 - 8 } & Stress in rotary plane & 1.5842 & 1.9344 & 2.1168 & 2.0206 & 2.0118 & 1.4437 \\
\cline { 2 - 8 } & Stress in amplitude plane & 32.1655 & 12.3643 & 38.1336 & 44.4141 & 52.1274 & 97.2886 \\
\hline \multirow{2}{*}{$\begin{array}{c}\text { The center } \\
\text { of gravity } \\
\text { dangerous } \\
\text { section }\end{array}$} & Total stress & 252.0288 & 290.3315 & 323.0246 & 319.1557 & 321.0928 & 295.5309 \\
\cline { 2 - 8 } & Axial stress & 230.6570 & 256.9178 & 269.9370 & 261.4883 & 257.4131 & 192.5497 \\
\cline { 2 - 8 } & Stress in rotary plane & 10.1652 & 12.1605 & 13.1972 & 12.6237 & 12.5583 & 9.1605 \\
\hline \multirow{3}{*}{$\begin{array}{c}\text { The root } \\
\text { dangerous } \\
\text { section }\end{array}$} & Total stress & 256.3881 & 296.8114 & 318.9849 & 312.7620 & 311.7983 & 270.7484 \\
\cline { 2 - 8 } & Axial stress & 238.4737 & 264.0067 & 276.6336 & 268.0656 & 263.8438 & 197.2108 \\
\cline { 2 - 8 } & Stress in rotary plane & 16.8547 & 19.7450 & 21.2426 & 20.3625 & 20.2380 & 14.9991 \\
\cline { 2 - 8 } & Stress in amplitude plane & 1.0597 & 13.0598 & 21.1086 & 24.3339 & 27.7165 & 58.5385 \\
\hline
\end{tabular}

Table 7. Analysis of the overall stability stress of allowable stress method based on nonlinear theory

\begin{tabular}{|c|c|c|c|c|c|c|c|}
\hline \multicolumn{2}{|c|}{ Condition No. } & 1 & 2 & 3 & 4 & 5 & 6 \\
\hline \multirow{2}{*}{$\begin{array}{c}\text { The head } \\
\text { dangerous } \\
\text { section }\end{array}$} & Total stress & 200.1164 & 211.1730 & 241.0002 & 239.2158 & 241.9770 & 228.2847 \\
\cline { 2 - 8 } & Axial stress & 176.9447 & 198.4161 & 209.0856 & 202.6328 & 199.6274 & 150.9549 \\
\cline { 2 - 8 } & Stress in rotary plane & 1.1030 & 1.3190 & 1.4319 & 1.3700 & 1.3684 & 1.0036 \\
\hline \multirow{2}{*}{$\begin{array}{c}\text { The } \\
\text { center of } \\
\text { gravity } \\
\text { dangerous } \\
\text { section }\end{array}$} & Stress in amplitude plane & 22.0686 & 11.4379 & 30.4827 & 35.2130 & 40.9812 & 76.3262 \\
\cline { 2 - 8 } & Total stress & 195.3126 & 232.1390 & 257.3730 & 254.4753 & 256.0456 & 238.6048 \\
\hline \multirow{nyyyyyyy}{*}{$\begin{array}{c}\text { The root } \\
\text { dangerous } \\
\text { section }\end{array}$} & Stress in rotary plane & 7.1541 & 8.3838 & 9.0254 & 8.6602 & 8.6435 & 6.4800 \\
\cline { 2 - 8 } & Stress in amplitude plane & 5.2819 & 19.9595 & 34.1802 & 38.1910 & 42.8946 & 77.6328 \\
\cline { 2 - 8 } & Stral stress & 204.0518 & 237.8755 & 255.3989 & 250.7701 & 250.2120 & 220.9264 \\
\cline { 2 - 8 } & Stress in amplitude plane & 2.0905 & 13.8761 & 20.4571 & 23.0342 & 25.7648 & 51.4069 \\
\hline
\end{tabular}

Note: Total stress $=$ Axial stress + Stress in rotary plane+ Stress in amplitude plane, the unit of stress is MPa.

For an intuitive analysis of the cause for above phenomenon, the percentage of each stress is gotten from Table 6 and Table 7, as shown in Fig. 4 Fig. 6. Simultaneously, the sum of stress in rotary plane and stress in amplitude plane caused by bending moment is considered as an additional stress, which can make it easy to compare.

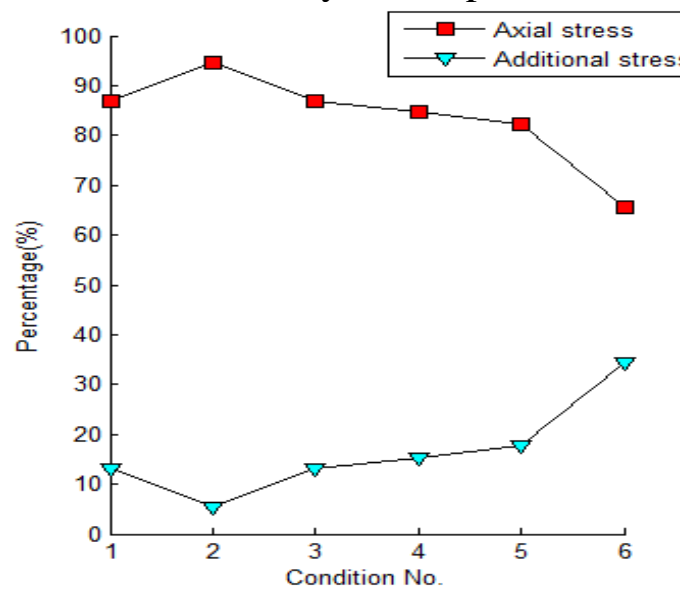

(a) Limit state method based on nonlinear theory

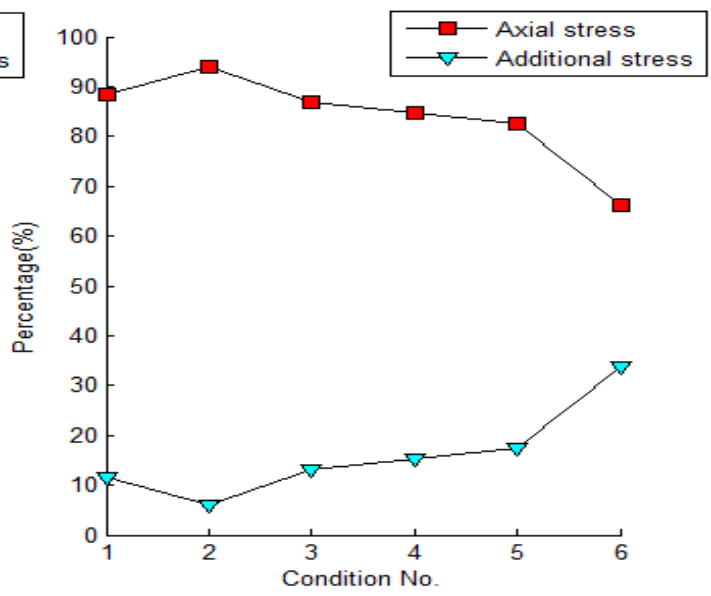

(b) Allowable stress method based on nonlinear theory

Figure 4. Proportion of overall stability stress of the head dangerous section 


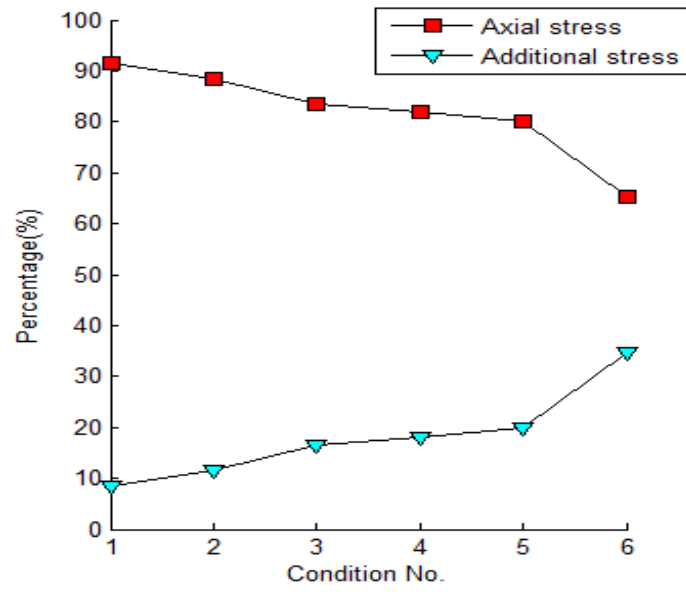

(a) Limit state method based on nonlinear theory

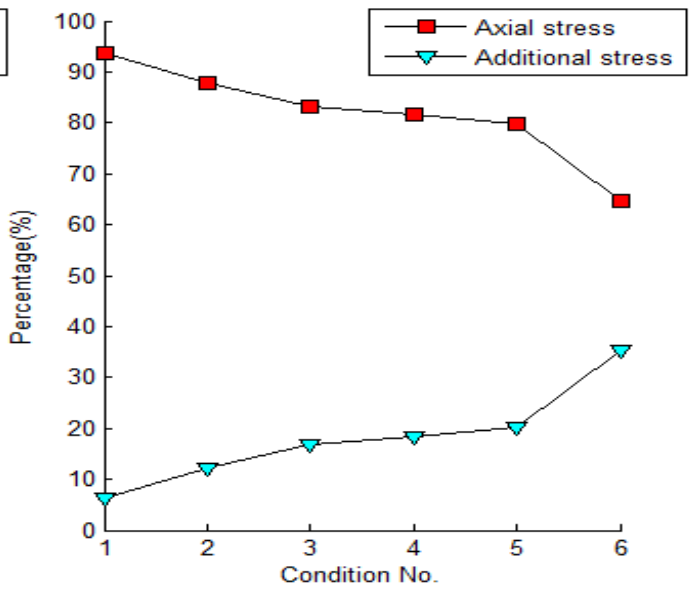

(b) Allowable stress method based on nonlinear theory

Figure 5. Proportion of overall stability stress of the center of gravity dangerous section
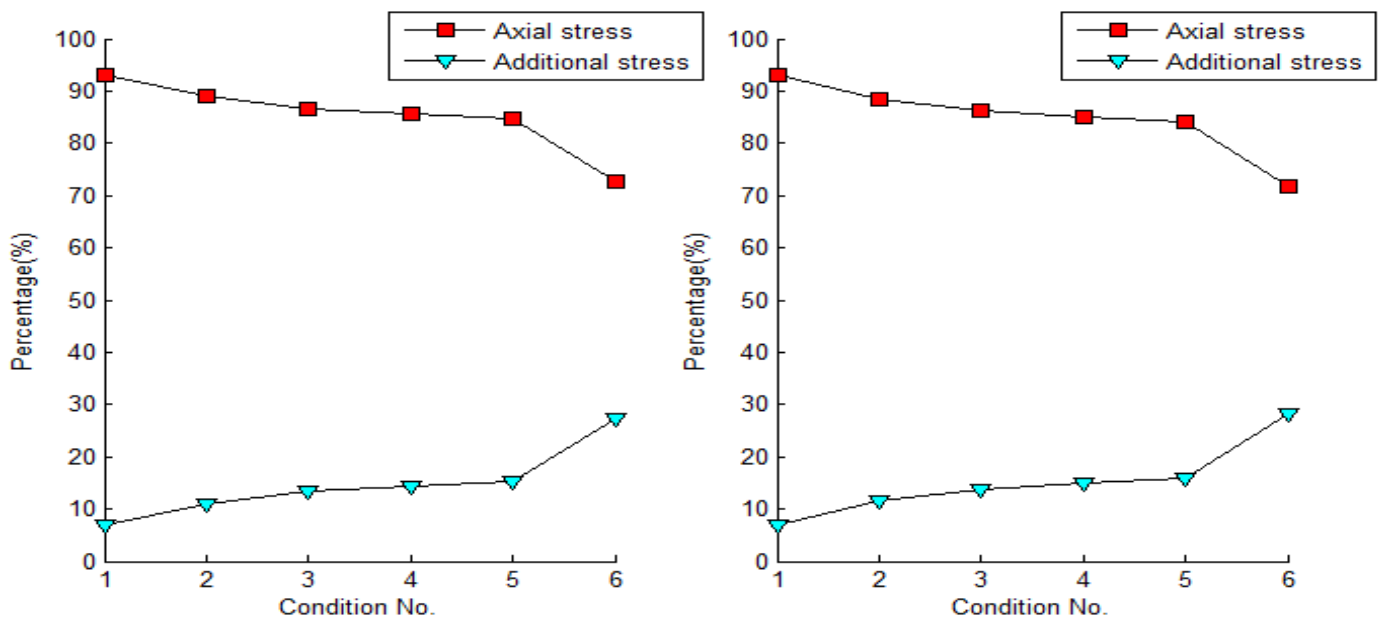

(a) Limit state method based on nonlinear theory

(b) Allowable stress method based on nonlinear theory

Figure 6. Proportion of overall stability stress of the root dangerous section

From the data gotten by comparative analysis of the data in Fig. 4 Fig. 6, with the reduction of boom elevation angle (the increase of condition No.), the percentage of axial stress $\sigma_{N}=N / \varphi A$ in total stress decreases, on the contrary, the percentage of additional stress $\sigma_{M}=M /\left(\left(1-N / N_{E}\right) W\right)_{\text {in }}$ total stress rises, that is to say, structural nonlinearity lowers with the reduction of elevation angle. For condition No.1 condition No.3, the elevation angle is relatively larger and structural nonlinearity is much higher, as a result, the percentage of axial stress $\sigma_{N}=N / \varphi A$ in total stress is larger while the percentage of additional stress $\sigma_{M}=M /\left(\left(1-N / N_{E}\right) W\right)_{\text {in }}$ total stress is smaller. Nevertheless, the data in condition No.4 condition No.6 have the opposite characteristics compared with condition No.1 condition No.3. Therefore, to some degree, the limit state method based on nonlinear theory and allowable stress method based on nonlinear theory are proved to be scientific and adaptive.

To further demonstrate the suitability and adaption of limit state method based on nonlinear theory for the stability calculation of lattice boom, a numerical simulation under 6 kinds of working condition (as shown in Table 3 ) is performed based on limit state method ANSYS. Considering that the overall stability stress in dangerous section cannot be calculated by using ANSYS, it is better to extract the single limb stability stress in each dangerous section to compare with analytic solution of the single limb stability stress calculated by limit state method based on nonlinear theory. The results of comparison are listed in Table 8 Table 10.

From the data in Table 8 Table 10, it can be observed that the error $\varepsilon$ between $\sigma \mathrm{J}$ and $\sigma \mathrm{A}$ is less 
than 5\% which is within the allowed range, the main reasons for error-making are as follows:

1) Analytic solution $\sigma \mathrm{J}$ based on the second order nonlinear theory fully considers the second order stress caused by the deformation of biaxial bending and the additional stress generated from the geometric features of structural section through the moment amplification coefficient and stability coefficient while the finite element modeling is relatively ideal, it does not take the influence caused by the eccentric load and geometric features of structural section into account, so the calculated value is relatively small.

2) ANSYS solution $\sigma$ A uses branch buckling load based on the first class stable, namely the Euler critical force of centrally loaded columns, and fails to apply the second class stable compressive load of eccentrically loaded columns which is being in exploration period for the stability calculation of lattice boom, but finite element method results, the powerful simulation validation of analytical solution and CAE technology, can visually display the stress distribution in each key section and component of the lattice boom.

Table 8. Comparison of head dangerous section

\begin{tabular}{|c|c|c|c|}
\hline Condition No. & $\sigma_{J}(\mathrm{MPa})$ & $\sigma_{A}(\mathrm{MPa})$ & $\varepsilon(\%)$ \\
\hline 1 & 216.8399 & 212.211 & 2.135 \\
\hline 2 & 214.4220 & 207.132 & 3.400 \\
\hline 3 & 256.4090 & 248.564 & 3.060 \\
\hline 4 & 257.2320 & 249.443 & 3.028 \\
\hline 5 & 263.3386 & 251.732 & 4.407 \\
\hline 6 & 263.5259 & 255.327 & 3.111 \\
\hline
\end{tabular}

Table 9. Comparison of center of gravity dangerous section

\begin{tabular}{|c|c|c|c|}
\hline Condition No. & $\sigma_{J}(\mathrm{MPa})$ & $\sigma_{A}(\mathrm{MPa})$ & $\varepsilon(\%)$ \\
\hline 1 & 203.0394 & 196.712 & 3.116 \\
\hline 2 & 237.9500 & 231.431 & 2.740 \\
\hline 3 & 273.0119 & 265.561 & 2.729 \\
\hline 4 & 272.1453 & 263.342 & 3.235 \\
\hline 5 & 276.3969 & 266.741 & 3.493 \\
\hline 6 & 270.2648 & 260.773 & 3.512 \\
\hline
\end{tabular}

Table 10. Comparison of root dangerous section

\begin{tabular}{|c|c|c|c|}
\hline Condition No. & $\sigma_{J}(\mathrm{MPa})$ & $\sigma_{A}(\mathrm{MPa})$ & $\varepsilon(\%)$ \\
\hline 1 & 195.4619 & 191.273 & 2.143 \\
\hline 2 & 233.6149 & 229.780 & 1.642 \\
\hline 3 & 257.2565 & 248.912 & 3.244 \\
\hline 4 & 254.3042 & 246.221 & 3.179 \\
\hline 5 & 255.7084 & 247.823 & 3.084 \\
\hline 6 & 236.5552 & 226.881 & 4.090 \\
\hline
\end{tabular}

Note: $\varepsilon=\left|\sigma_{J}-\sigma_{A}\right| / \sigma_{J} \times 100 \%$, where, $\sigma_{J}$ is analytic solution of single limb stability stress, $\sigma_{A}$ is ANSYS solution of single limb stability stress.

\section{Conclusions}

1) Compared with traditional allowable stress method, the limit state method on the basis of probability theory is more suitable for the occasion in which the relationship between load and internal force is nonlinear. This method can accurately consider the roles of load, mechanical properties of steel material, performing characteristics of structure and other factors for the lattice boom using partial load coefficient and resistance coefficient instead of the single safety coefficient to calculate the stability. The calculating results are more in line with actual situation.

2) The limit state method based on nonlinear theory can take into full account the second order stress caused by the deformation of biaxial bending and the additional stress generated from geometric features of structural section through the moment amplification coefficient and stability coefficient, and the economical efficiency of structure with enough safety stocks are ensured by adopting this method. 
3) As shown in Fig. 4 Fig. 6, with the decline of structural nonlinearity, the fairly perfect results can be given by means of allowable stress method.

\section{References}

[1] Zhengyuan Zhang. Linear and nonlinear deformation and internal force of two- hanging point horizontal boom of tower crane, Journal of Tong Ji University, Papers 28(6), 731-737 (2000)

[2] Dashuai Chang. Nonlinear stability analysis of crane lattice boom, Shenyang: Northeastern University (2011)

[3] GB/T3811-2008, Design Rules for Cranes, Beijing, Standards Press of China (2008)

[4] Gening Xu. Machinery Equipment Metal Structure Design, Beijing, Mechanical Industry Press of China (2009)

[5] GB/T22437.4-2010, Crane Load and Load Combination Design Principles-Part 4: Boom Crane, Beijing, Mechanical Industry Press of China (2011)

[6] GB/T 30024-2013, the Test of Crane Metal Structure Ability, Beijing, Mechanical Industry Press of China (2014)

[7] Qicai Zhou, Wenjun Li, Zailei Zhou, Xiaolei Xiong. Linear stability analysis of space compressive structure of a inverted-v combinatorial jib, Chinese Journal of Mechanical Engineering, Papers 23(24), 3323-3328 (2013)

[8] Gang Wang, Zhaohui QI, Xin Wang. Load-carrying capacity of hinged boom structures for crawler cranes, Journal of Mechanical Engineering, Papers 51(3), 111-120 (2015)

[9] Gang Wang, Zhaohui Qi, Xianchao Kong. Geometrical nonlinear and stability analysis for slender frame structures of crawler cranes, Engineering Structures, Papers 51(83), 209-222 (2015)

[10] F. Dau, O. Polit, M. Touratier.C1 plate and shell finite elements for geometrically nonlinear analysis of multilayered structures, Computers and Structures, Papers 2006(84), 1264-1274 (2006)

[11] Li Z, A stabilized co-rotational curved quadrilateral composite shell element, International Journal for Numerical Methods in Engineering, Papers 86(8), 975-999 (2011)

[12] Guangfu Su, Michael Kleeberger, Jie Liu. Complete dynamic calculation of lattice mobile crane during hoisting motion, Mechanism and Machine Theory, Papers 40(6), 447-466 (2005)

[13] Timoshenko SP, Gere JM. Theory of elastic stability, New York: Mc Graw-Hill (1961) 